\title{
Cuentas polícromas prerromanas decoradas con «ojos»
}

\author{
Encarnación Ruano Ruiz *
}

\section{RESUMEN}

El artículo ofrece algunas precisiones de carácter técnico sobre la fabricación de cuentas de collar oculadas prerromanas. Analiza los materiales procedentes de la necrópolis ibérica de El Cigarralejo (Mula, Murcia) y sugiere para este tipo de adorno algunas connotaciones sociales y religiosas.

\section{ABSTRACT}

The article offers some technical precisions about pre-roman eye form necklace beads manufacturing. It analyzes the materials obtained in the Iberian graveyard in El Cigarralejo (Mula, Murcia) and suggest, for this kind of adormaments, some social and religious purposes.

"La sabiduría no la igualan ni el oro, ni el vidrio/ni cabe cambiarla por vaso de oro fino"

(Job XXVIII, 17)

\section{INTRODUCCIÓN}

Las cuentas decoradas con "ojos" encontradas en la Península pertenecen a un tipo común de adornos usados desde épocas remotas formando parte de collares. La llamativa decoración polícroma de estas perlas ha

* Directora del Boletín de la Asociación Española de Amigos de la Arqueología. Dedicado a la investigadora Ana Ma Muñoz Amilibia. 
hecho posible indentificarlas dentro de los conjuntos de cuentas monócromas que han pasado más desapercibidas. El estudio pormenorizado de las piezas no se habia realizado hasta el momento '.

La fabricación de cuentas de collar no es muy conocida, por lo que incluimos algunas precisiones de carácter técnico.

La distribución histórica de las cuentas oculadas permitirá valorar mejor los hallazgos de El Cigarralejo por lo que hemos incluido un mapa de dispersión en el que se contemplan los yacimientos con estas clases de adorno, tratando de presentar los materiales de una manera ordenada en el tiempo y en el espacio.

Los objetos de vidrio encontrados en las últimas excavaciones sistemáticas realizadas por E. Cuadrado en la necrópolis de El Cigarralejo fueron puestos a nuestra disposición para su estudio, hecho que ha facilitado el contacto directo con las cuentas oculadas aparecidas en tumbas con una cronología relativa del siglo $\mathrm{V}$ al II a.C. fecha que se dejó de enterrar en la necrópolis. Se han tenido en cuenta en los cómputos generales otras piezas policromas decoradas con «ojos» con cronologías más precisas halladas en las tumbas del cementerio ibérico publicadas por el doctor E. Cuadrado (1987).

\section{HISTORIA DE LA INVESTIGACIÓN}

La primera vez que aparecen mencionadas en la bibliografía las cuentas de "ojos" es en el año 1908 donde Kisa recoge diferentes tipos de esta clase de adornos.

El primer y único estudio dedicado exclusivamente a las cuentas denominadas de «ojos» fue el realizado por Eisen (1916), el investigador basó su clasificación en principios tecnológicos. En 1928 Beck dedicó un extenso artículo sobre las cuentas de collar incluyendo las de "ojos".

Haevernick en diferentes trabajos 1972, 1947a, y 1974b, examinó las cuentas de Eslovenia, las procedentes de Dürnberg cerca de Hallein y dedicó un estudio especial a las cuentas de "ojos" compuestas. Aleksejeva en 1975 y 1978 estudia ornamentos de cristal del Norte del Mar Negro, incluyendo la información de las cuentas oculadas.

\footnotetext{
- En noviembre de 1944 presentamos al International Perlenkolloquium celebrado en el Museo Reiss de Mannheim (Alemania) la ponencia titulada "Perles en verre prérromaines provenant de la nécropole iberique de El Cigarralejo, Mula, Murcia (España). Por primera vez se ofrece un mapa de dispersión de las cuentas oculadas.
} 
En 1983 Natalia Venclová dedica un artículo a la cuentas de «ojos" en Europa Central. Es en 1985 cuando Maud Spaer estudia las perlas estratificadas del primer milenio a.C.

En ninguno de estos trabajos se alude a las cuentas de ojos españolas sólo existe una breve nota escrita por la doctora Haevernick en 1961 con el título "Cuentas de vidrio en el Museo Arqueológico Nacional de Madrid» donde se hace una sumaria referencia a las cuentas multicolores: "Entre las cuentas oculadas con más o menos adornos, hay pocas especies que se hallen verdaderamente extendidas y sean frecuentes. Estas son sobre todo las cuentas de color amarillo opaco, con «ojos» estratificados de color azul y blanco. Pero es importante hacer distinciones incluso entre ellas. La mayor parte de las cuentas de esta especie tiene una serie o dos de "ojos" estratificados por cada ojo, dos veces o a veces tres. Pero en Villaricos y en Ibiza hay cuentas mucho más estratificadas y que probablemente no lo están en azul y blanco sino en pardo y blanco" (HAEVERNICK, 1961, 210).

\section{ALGUNAS CONSIDERACIONES GENERALES DE CARÁCTER TÉCNICO SOBRE LA ELABORACIÓN DE LAS CUENTAS DE COLLAR}

De todos es conocido los detalles sobre la composición y elaboración del vidrio, sólo unas líneas para recordarlo. El vidrio es una disolución sólida compuesta de sílice, cal y óxidos alcalinos a los que se añaden pequeñas proporciones de otros minerales. No posee punto de fusión fijo, es una sustancia rígida, pero no cristalina y entre sus propiedades destacan su gran dureza, transparencia y resistencia al desgaste y compresión.

«En la obtención del vidrio perromano la sílice se utilizó en forma de arena de cuarzo y cuarcita, los de cuarzo suelen ser transparentes mientras que los elaborados a base de arena son opacos y mal denominados pasta vitrea como si se tratara de otra materia distinta del vidrio en su composición. Como óxidos alcalinos se usó la sosa y la potasa, si bien la mayoría de los vidrios son de base sódica, con alto porcentaje de sosa para obtener un punto de fusión bajo. La cal o caliza con frecuencia lleva algo de magnesio. A estos componentes se les suele añadir otros secundarios, como los llamados agentes colorantes (metales coloidales, óxidos metálicos y sales) que trasmiten al vidrio los distintos colores y tonalidades conocidos, ya que su color natural es el verde azulado" (BARTHELEMHY, 1992, 29).

El vidrio coloreado o decolorado requiere como antes hemos apuntado de sustancias minerales específicas. El vidrio blanco opaco se colorea con 
antimonio para mayor economía y con óxido de estaño o fosfato. Los colores azules se obtenian añadiendo al material en fusión minerales de cobre. El color azul marino fue muy frecuente en vasos y cuentas prerromanas y estaba conseguido por la existencia simultánea de óxido ferroso y férrico. Los colores verdes con la mezcla de minerales de cobre y de hierro. Para la obtención de un vidrio negro se precisa grandes cantidades de mineral de hierro, al calentarlo da un negro rojizo oscuro o bien cantidades de cobre y manganeso unidas (GONZÁLEZ PENA, 1984, 29).

La forma de fabricación de objetos de vidrio se remonta a mediados del tercer milenio a.C., según demuestran los hallazgos arqueológicos realizados en Egipto y Mesopotamia, se desarrolla y llega a un grado de perfeccionamiento en Egipto en el año 1560 y 1460 en tiempos de Amenhotep I y Thumes III a Amenhotep IV.

\section{Elaboración de las cuentas de collar}

La fabricación de cuentas de collar es menos conocida. Sleen en 1973 dedica un capítulo de su obra a la elaboración de estos bellos adornos: "Cuando se ha realizado la mezcla de elementos en el crisol se somete a la acción del fuego hasta que la materia queda derretida y convertida en una masa roja de vidrio viscoso. Un trabajador agita la mezcla con una barra de hierro hasta que recoge una porción de vidrio derretido, donde inserta una segunda barra de hierro y dá la barra a otro trabajador convirtiéndose la masa viscosa en una varilla de vidrio que se solidifica antes de que toque el suelo. Tan rápido como el artesano realice la operación, más fina será la varilla. La longitud puede alcanzar los $100 \mathrm{cms}$. el diámetro varía de 1 a $12 \mathrm{~mm}$. Estas largas varillas suelen cortarse en trozos de 60 a $90 \mathrm{cms}$. convirtiéndolas en materia prima para fabricar las más antiguas y simples cuentas llamadas "cuentas enrolladas».

Las varillas de vidrio se derriten en un extremo y se doblan alrededor de un alambre de cobre o hierro que se sujeta con la otra mano. Cuando los anillos de cristal están cerrados en torno al alambre, se corta el resto de la varilla y se calienta el anillo de vidrio quedando una perfecta forma oval o redonda. Una vez que los anillos se han colocado alrededor del alambre, se dejan a un lado para que se enfrien. En el enfriado el metal se contrae más que el vidrio y las cuentas se pueden resquebrajar. De acuerdo con el diámetro del alambre la perforación es de mayor o menor tamaño. Las cuentas de mayor tamaño se podrían hacer enrollando una varilla de $1 \mathrm{~mm}$. $02 \mathrm{~mm}$. varias veces alrededor del alambre (Fig. 1-2). 

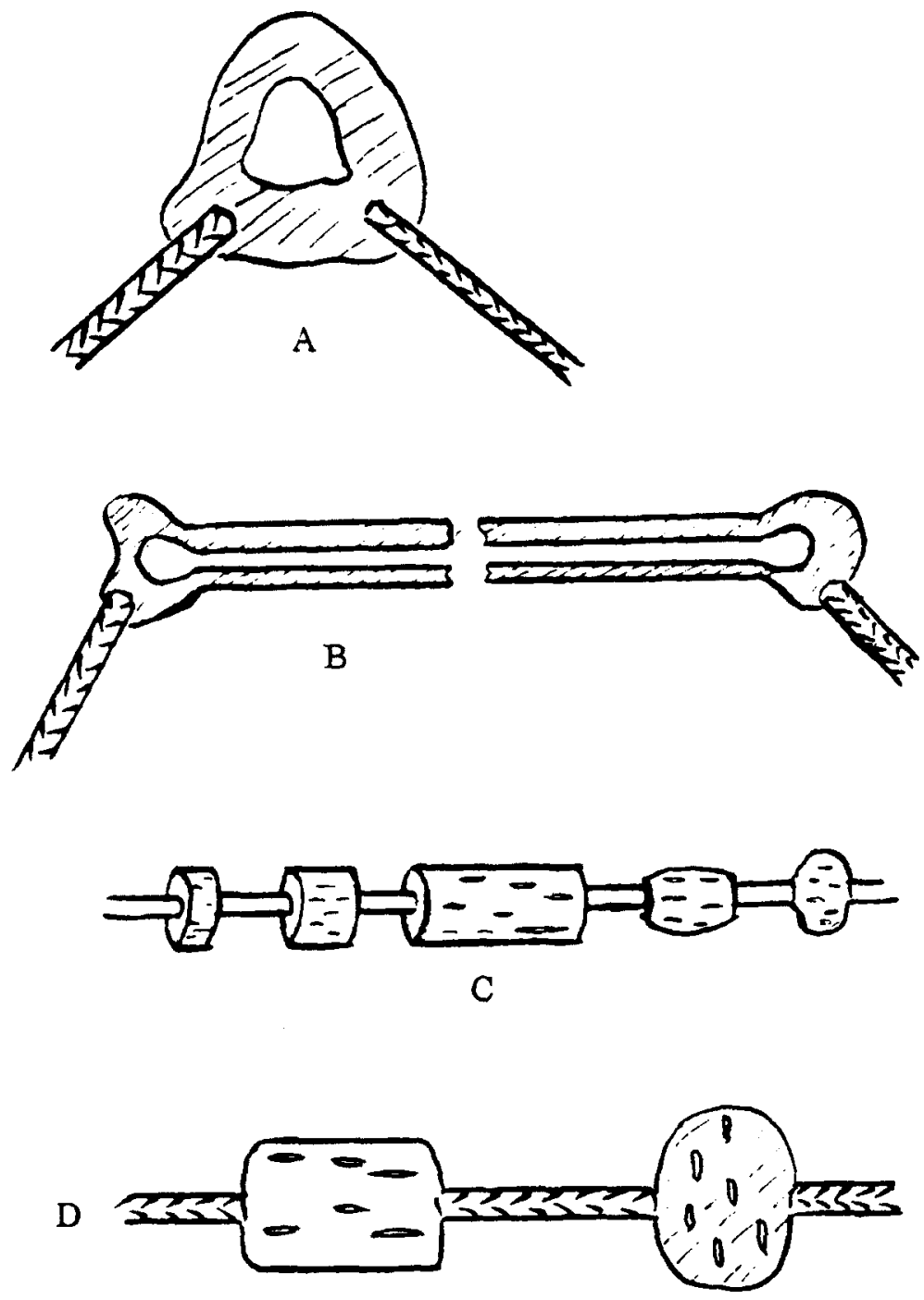

Figura 1. Fabricación de las cuentas de vidrio (Sleen, 1973). 

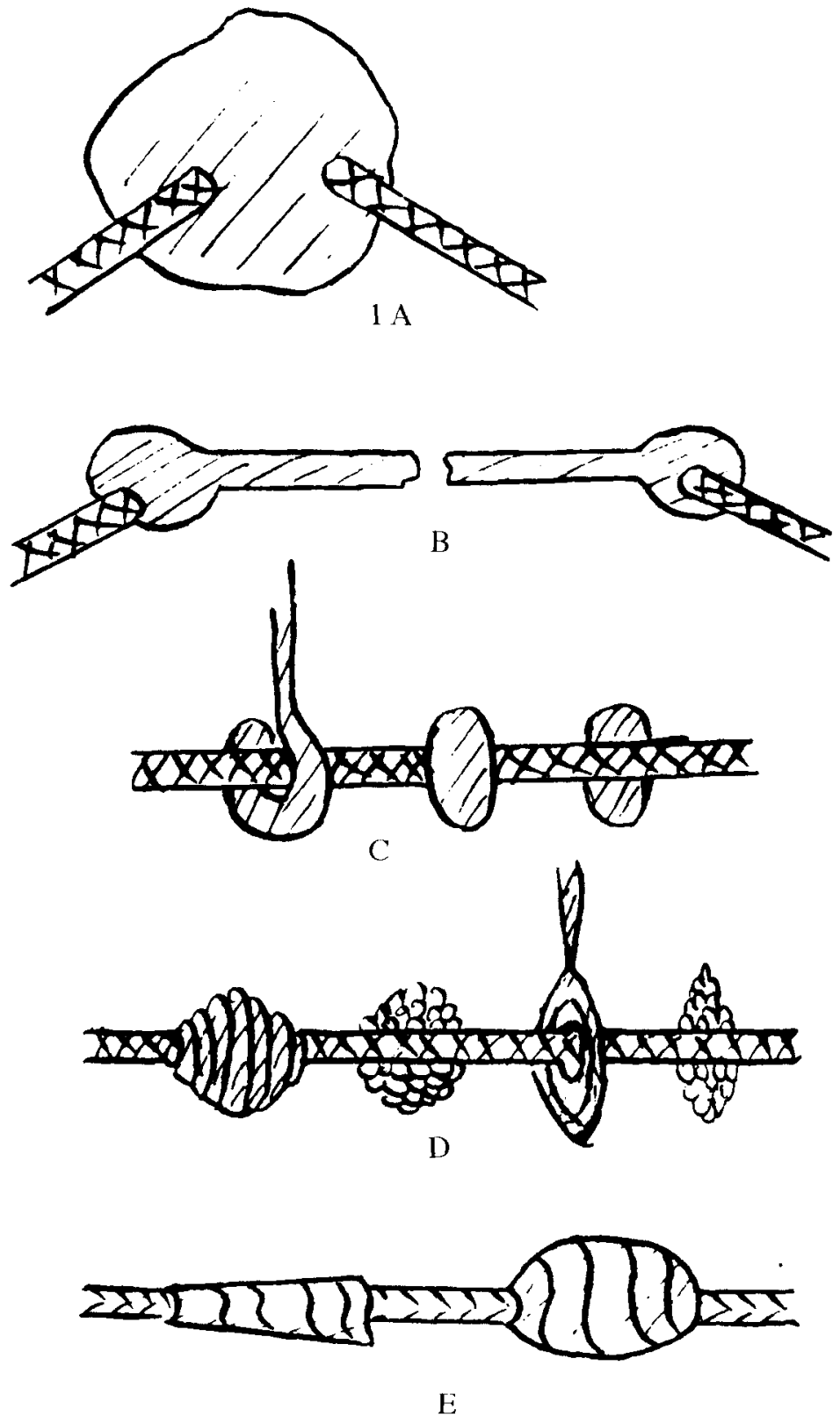

Figura 2. Fabricación de las cuentas de vidrio (Sleen, 1973). 
Esta forma de hacer cuentas es totalmente artesanal y se realizan manualmente de una en una, como podemos ver en el esquema propuesto por el Oldaksamlingen, Historisk Museum, Universitetet, Oslo (Fig. 3).
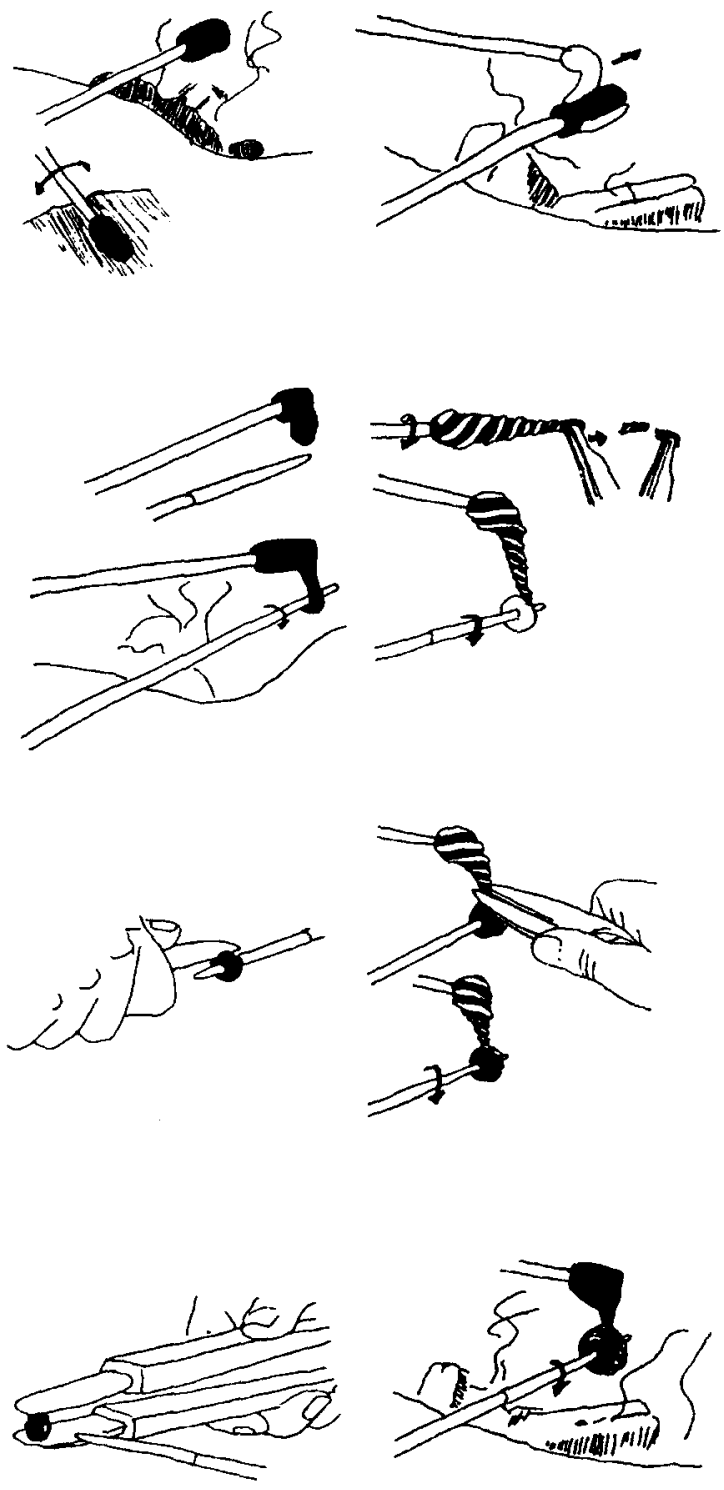

Figura 3. Esquema de la elaboración de las cuentas de collar según el Oldaksamlingen, Historik Museum, Universitetet, Oslo. 
2. Fabricación de las cuentas de "ojos"

La técnica empleada para la elaboración de las cuentas de "ojos" fue estudiada por Eisen como ya apuntamos en la introducción.

Es fundamental para el conocimiento y clasificación de las cuentas oculadas españolas conocer de una manera general las categorías que señala el investigador en la ejecución de estos adornos: 1) simple; 2) con "ojos" estratificados; 3) con "ojos" mosaico".

1) Las cuenta de «ojo» simple aparecen como gotas de cristal o como anillos impresos en el interior de una cuenta matriz. El sistema de elaboración de estas cuentas tan antiguas permite que los "ojos" se desprendan con cierta frecuencia.

2) Las cuentas con "ojos" estratificados eran muy populares entre los egipcios, su aparición se sitúa hacia el año 1500. Los fenicios y los chinos las usaron durante por los menos el primer milenio a.C. En este caso la elaboración de la cuenta se hacia mediante la inclusión de una gota de cristal puesta en una matriz, la gota era empujada dentro, mientras la matriz estaba blanda y otra gota se introducía en el interior de la primera. El resultado final era la sucesión de círculos concéntricos, con un punto central más oscuro y espeso.

En algunos casos los "ojos" se construian por separado y después se incluian en la matriz.

3) Los "ojos" denominados mosaico aparecieron hacia el siglo $\mathrm{V}$ a.C. pero no fueron comunes hasta el año 200 a.C. que empezaron a sustituir a los «ojos» estratificados, proceso que se completó en época romana.

De esos tres tipos de cuentas mencionados debemos incidir en el segundo es decir en las cuentas de "ojos" estratificadas. La mayoría de las cuentas multicolores encontradas en la Península parecen haberse realizado con esta técnica, no podemos descartar la existencia de cuentas oculadas con otras características. Los "ojos" estaban realizados colocando sobre la matriz una gota de cristal y enrollándola en ella mientras la matriz estaba blanda. En lo alto de esta zona otra gota de diferente color se situaba y enrollaba de la misma manera. Cuando el «ojo» había recibido tantas gotas superpuestas como se quisiera, las gotas se alisaban para permitir que las capas más profundas aparecieran en la superficie como anillos. Sin embargo si las gotas se habian colocado correctamente de mayor a menor, no era necesario. En algunos casos parece que el "ojo" entero se hizo separadamente y entonces fue presionado en la matriz de la cuenta, o la cuenta puede estar hecha de varios estratos de gotas superpuestos, previamente triturados, "ojos" con 
las mismas características datan de la XIX Dinastía egipcia y continúan usándose hasta los Ptolomeos, más tarde con el tiempo el proceso cayó en desuso. La técnica de cortar varas decoradas previamente permitía al artesano producir "ojos" más fácilmente y con menos pericia.

\section{Diferentes tipos de cuentas de ojos estratificados según Eisen}

La clasificación de Eisen es bastante descriptiva y ayuda a interpretar los diferentes tipos de cuentas de "ojos". Tomando como base lo expuesto por el autor, hemos realizado un cuadro que permite ver de una manera gráfica los distintos modelos de cuentas de «ojos» (Fig. 4).

\begin{tabular}{|c|c|c|c|c|c|c|c|c|}
\hline $\mathbf{A}$ & B & C & D & $E$ & $\mathbf{G}$ & $\mathbf{H}$ & $\boldsymbol{J}$ & $\mathbf{L}$ \\
\hline (9) & $\begin{array}{l}\text { (9) } \\
\text { (6) } \\
\text { (60) }\end{array}$ & 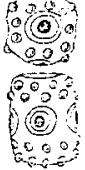 & 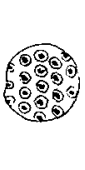 & $\frac{16}{6}$ & (1) & $\begin{array}{r}10 \% \\
096 \\
096 \\
00 \% \\
\end{array}$ & 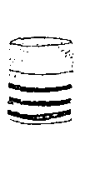 & 3 \\
\hline
\end{tabular}

Figura 4. Diferentes tipos de cuentas estratificadas (Eisen, 1916 b). Esquema interpretado por E. Ruano.

a) Separados y colocados en hilera alrededor de una cuenta (Fig. 4-A).

b) En dos hileras tan aproximados que parecen ojos de animales. Algunas veces alternan y tienen tres "ojos" en un extremo y cuatro "ojos" más pequeños en el extremo opuesto (Fig. 4-B).

c) Los «ojos» son sustituidos por nudos o protuberancias (Fig. 4-C).

d) Situados en muchas hileras paralelas (Fig. 4-D).

e) "Ojos" pequeños colocados en grupos en un campo delimitado y coloreado generalmente en color marrón. Estas cuentas son frecuentes en el siglo $V$ a.C. (Fig. 4-E).

f) Los "ojos" sobresalen mucho. La cuenta es generalmente cuadrada. Aparecen en el siglo $\mathrm{V}$ perdurando hasta el siglo III a.C.

g) Dos tipos alternantes de "ojos" diferentes coloreados. Uno de los "ojos" colocado solo. El otro en una sola hilera. Siglo V a.C. (Fig. 4-G).

h) Los «ojos» son pequeños y están elevados como nudos o protuberancias situados en hileras paralelas. Siglo V a.C. (Fig. 4-H).

j) Cuenta realizada con dos o tres esferitas oculadas y que presenta tres esquinas con ojos fuertemente salientes. Siglo III a.C. (Fig. 4-J). La figura representa uno de los nudos del "ojo". 
k) El "ojo" punto está formado mediante un escudo estratificado. Este tipo se da en dos períodos ampliamente separados. Dinastía egipcia XIX y los siglos IV y III a.C.

l) El «ojo» central está realizado con cristal dorado. Situados cronológicamente en los siglos III y II a.C. (Fig. 4-L).

\section{DISPERSIÓN GEOGRÁFICA DE LAS CUENTAS OCULADAS}

La distribución histórica de las cuentas oculadas refleja que las cuentas más antiguas y de mayor tamaño aparecieron en el Asia Occidental India y Egipto. A mediados del primer milenio pasaron a Europa y a determinados lugares del interior de China, presumiblemente reflejando influencias de Occidente, aunque existía una estrecha relación entre las palabras pupila y cuenta.

Las cuentas decoradas con "ojos" se encuentran en yacimientos españoles localizados en zonas peninsulares e insulares desde tiempos remotos hasta épocas cercanas a la romanización (Mapa № 1).

La cuenta oculada más antigua de la península está datada aproximadamente entre el 1400 y 1100 a.C. La perla es de fondo negro y tiene los adornos circulares de color blanco. Procede de un sepulcro megalítico de l'Alto Urgel (Cura Morera, 1973, 212-213) (Fig. 8.3).

En Peña Negra (Crevillente) se localizaron cuatro cuentas situadas cronológicamente entre los siglos VIII- VII a.C. En este caso las cuentas presentan un contorno triangular con ángulos romos y en los lados sobresalen los "ojos". El fondo es azul y los "ojos"se han perdido (GonzÁLEZ PRAT, 1983). La procedencia de la cuenta pudiera ser centroeuropea. Existen numerosas cuentas con características semejantes recogidas en un estudio publicado por Venclovà (1983).

En Medellín (Badajoz) se encontró una cuenta verde en la tumba 19 fechada por Almagro Gorbea entre el 500-475 a.C. (1976; 1989). En la provincia de Cuenca aparecieron en la necrópolis de Las Madrigueras (Carrascosa del Campo) en la tumba LXII fechada en el año 550-500 a.C., la cuenta tiene el fondo azul verdoso y está decorada con "ojos" realizados mediante tonos azul oscuro, blanco y azul ${ }^{2}$.

2 Las perlas con "ojos"aparecen a partir del Halistatt, pero el color azul es caracteristico sobre todo de la etapa de La Tene, hacia la cual nos inclinariamos a colocar nuestros ejemplares, sustituyendo el color amarillo que parece predominar en la época anterior. Esta hipótesis iria bien 


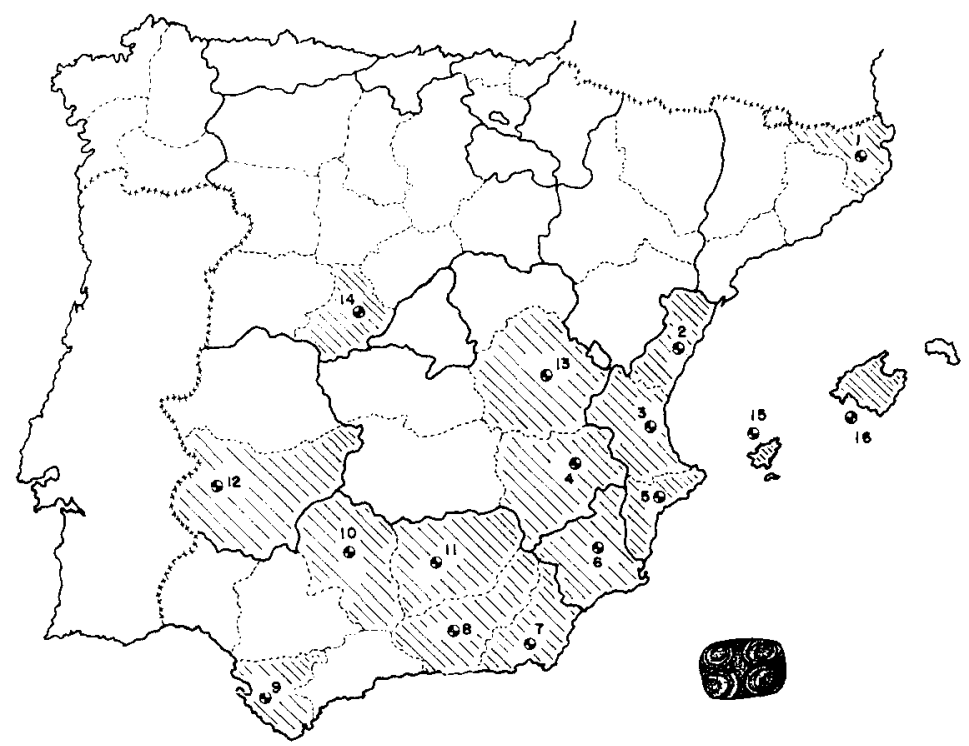

1. GERONA: Ampurias. Puig del Castellet (Lloret de Mar).

2. CASTELLÓN: Orley (Val de Uxó).

3. VALENCIA: Caudete de las Fuentes.

4. ALBACETE: Casa del Alcalde.

5. ALICANTE: Cabezo Lucero (Guardamar de Segura). Puntal de Salinas. La Albufereta. La Serreta (Alcoy). Peña Negra (Crevillente).

6. MURCIA: Cabecico del Tesoro (Verdolay). El Cigarralejo (Mula). Coimbra de Barranco Ancho (Jumilla). Los Nietos (Cartagena).

7. ALMERIA: Villaricos.

8. GRANADA: Puente Noy (Almuñecar).

9. CÁDIZ: Calle Tolosa Latour. Playa de los Números. La Algaida.

10. CORDOBA: Cerro de la Cruz (Almedinilla).

11. JAÉN: Baños de la Muela, Estacar de Robarinas. La Guardia. La Loma del Peinado (Casillas de Martos).

12. BADAJOZ: Cancho Roano (Zalamea La Serena). Castrejón de Capote (Higuera la Real).

13. CUENCA: Las Madrigueras (Carrascosa del Campo). El Pajaroncillo. Hoyas del Castillo.

14. ÁVILA: La Osera (Chamartín de la Sierra).

15. IBIZA: Puig des Molins.

16. MALLORCA: Son Real. Isla de los Porros.

\section{Mapa $N^{\circ}$ 1: Distribución espacial de las cuentas oculadas **.}

con la observación realizada en la cercana necrópolis de Carrascosa donde las perlas de color amarillo parecen en la primera Fase Carrascosa I, mientras que las piezas de color azul intenso 0 translúcido aparecen en la Fase Carrascosa II, y tal vez incluso en los últimos momentos, en todo caso no anteriores al siglo IV a.C. (ALMAGro-GorbeA, 1965, 98).

** Estando en prensa este artículo, se ha publicado un interesante trabajo realizado por $\mathrm{J}$. Rovira I PORT, "Ambar y pasta vítrea. Elementos de prestigio entre el Neolítico avanzado y el Bronce Final del Nordeste de la Península Ibérica. Un primer estado de la cuestión». Cuadernos de Prehistoria Castellonense, $n^{\circ} 16,67-90$. El autor confirma la aparición de cuentas oculadas en el Nordeste Peninsular, en fechas tempranas. 
Siguiendo precisiones cronológicas con dataciones que nos proporcionan contextos definidos, es en la isla de lbiza donde encontramos piezas con fechas antiguas del siglo VI a.C. concretamente en los hipogeos $\mathrm{N}^{\circ} 5$ y 7 de la necrópolis de Puig des Molins (GÓmez BELLARD, 1984, 13).

Con cronología mas recientes mediados del siglo $V$ y $I V$ a.C., se encuentran extendidas por toda la franja mediterránea; Andalucia y la Meseta. Si agrupamos por provincias los datos obtenidos a través de los datos bibliográficos y la consulta directa de la mayoria de las cuentas ${ }^{3}$ los resultados serian los siguientes:

GERONA: Las cuentas proceden en su mayoría de las necrópolis de Ampurias (tumbas: 20, 84, 94, 104, 112, 113, 133). Inhumación Martí (tumbas 20, 84, 94, 104, 112, 113, 133) (Almagro, 1953, 104) (Fig. 5). Bonjoan (tumba 53) y en la incineración Les Corts (tumbas 41 y 92) (ALMAGRO, 1953, 339).
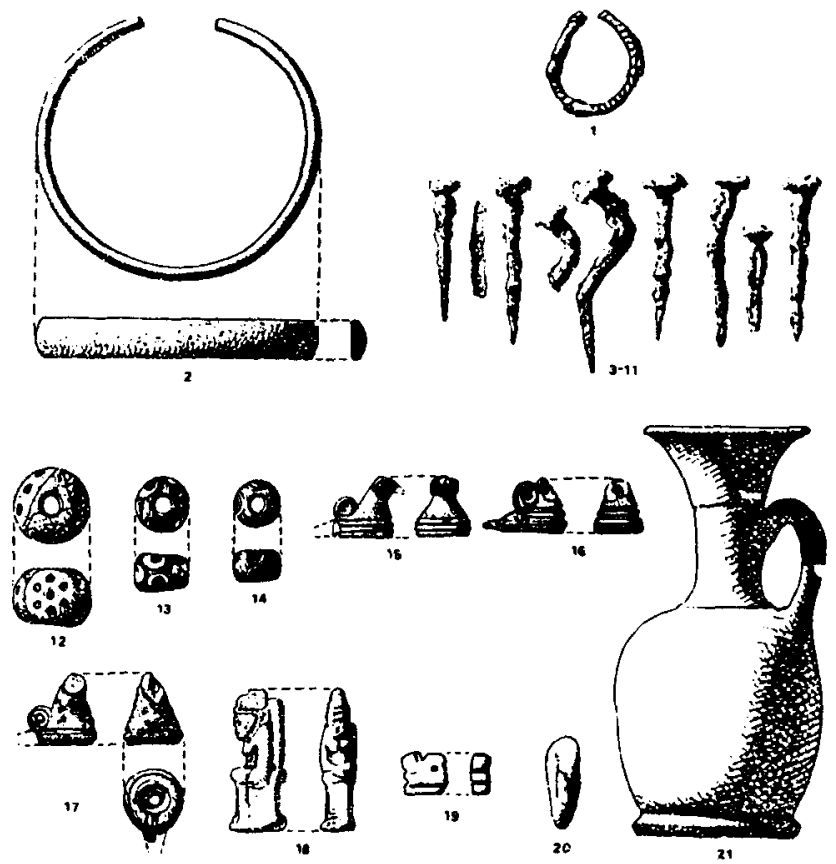

Figura 5. Ajuar de la tumba № 12 de la Inhumación Martí (Almagro 1953).

3 Expresamos nuestro agradecimiento a todos los directores de los Museos Arqueológicos que han permitido el acceso a las cuentas de collar, para realizar estos estudios. 


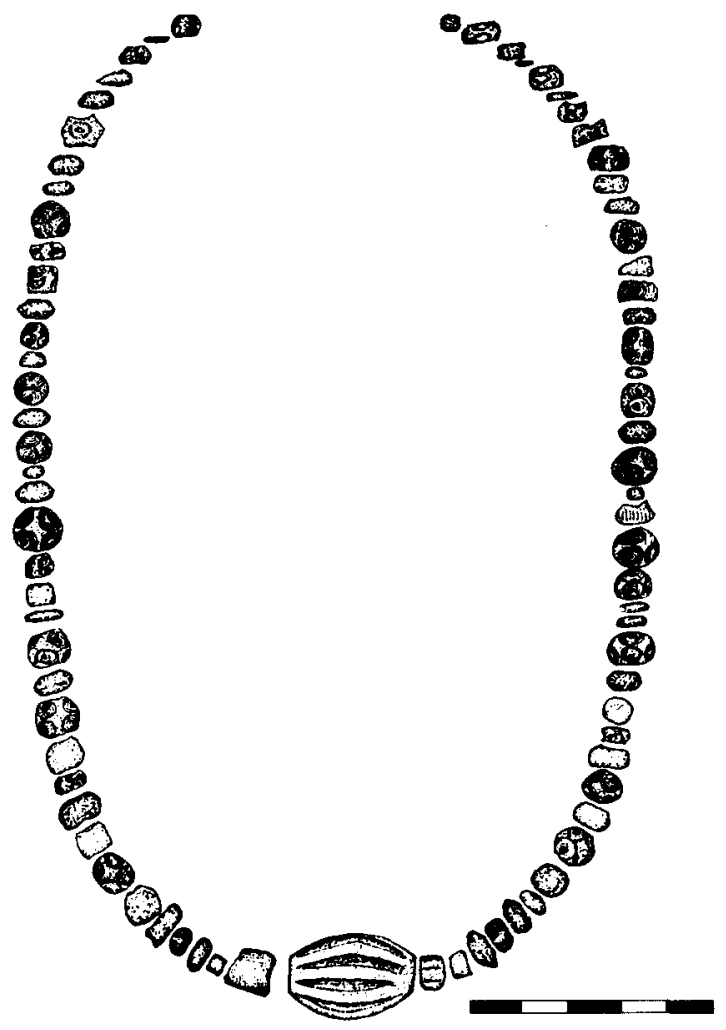

Figura 6. Collar realizado a partir de las cuentas halladas en la tumba № 5 de la zona B fechada en los siglos V-IV (Molina et alii, 1985).

Existen cuentas de “ojos" en el poblado del Puig del Castellet (Lloret de Mar) (Pujol, 1989).

CASTELLÓN: Punta de Orley (Val de Uxó) (Mengod et alii, 1981).

VALENCIA: Los Villares (Caudete de las Fuentes) (Mata, 1991).

ALBACETE: La Casa del Alcalde (GimÉnez Ortuño, 1984); El Tesorico (Agramunt) (Broncano et alii, 1985)

ALICANTE: Cabezo Lucero (Aranegui et alii, 1993); El Puntal de Salinas (SOLER GARCiA, 1992) La Albufereta (Alicante) (Tumbas 168, 127 y 140) (LAFUENTE, 1956; Figueras, 1956, 1957).

MURCIA: Cigarralejo (Fig. 8.2 y 4), Cabecico del Tesoro, Coimbra de Barranco de Ancho y Los Nietos (Cruz, 1990). 
ALMERÍA: En las necrópolis de Villaricos. Denominadas «cuentas de manchas" por M.Astruc. Aparecen en numerosas tumbas $(30,42,51,63$, $174,223,277,433,452,462,471,479,502,511,532,533,536,541$, $565,707,796,813,819,852,905,909,934,947,1082,1114,1675$ (ASTRUC, 1951).

GRANADA: Puente Noy (Almuñecar) (Molina FAJARDo et alii, 1982; 1984). (Fig. 6).

CÁDIZ: Calle Tolosa Latour (Perdigones el alii, 1990); Playa de los Números según Quintero Atauri” Entre los restos de las tierras del Hipogeo» (1932).

JAÉN: Cástulo: Baños de la Muela, en la sepultura XII fechada entre los siglos V-IV (BLÁZQUEZ, 1979) y en la necrópolis de El Estacar de Robarinas (BLÁZQUEZ, 1986). La Guardia (BLANCO, 1959); La Loma del Peinado (Casillas de Martos). Según Maluquer (1974) « La cuenta se encontró no lejos de la sepultura $n^{\circ} 8$ (Fig. 7).
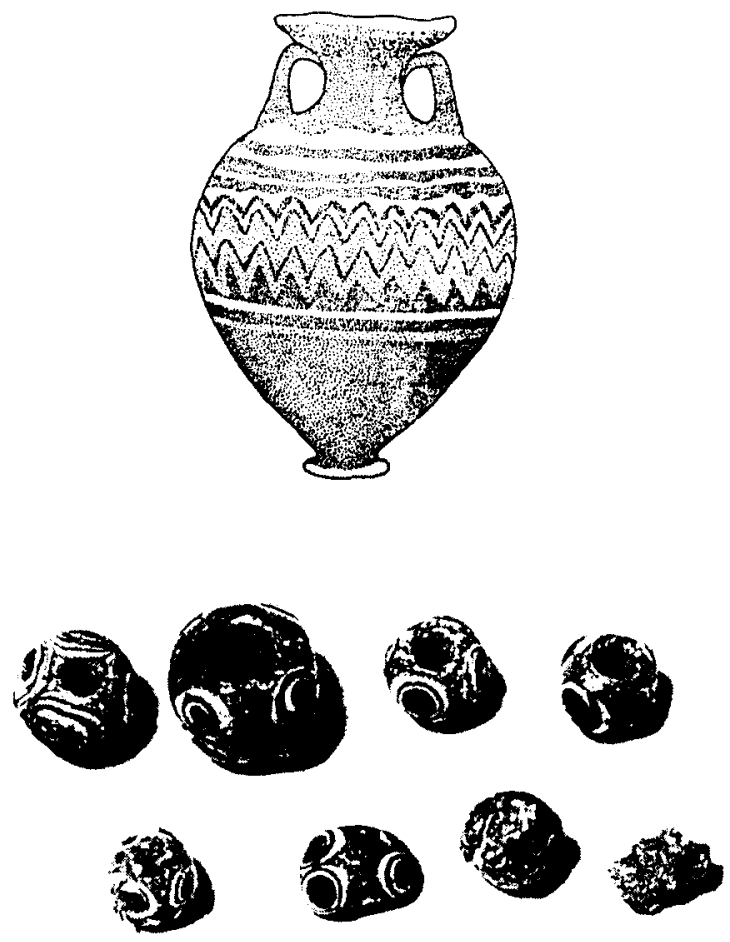

Figura 7. Cuentas oculadas halladas en la necrópolis de Casillas de Martos (La Loma del Peinado, Jaén) (MaluQuer, 1974). 
CÓRDOBA: En Almedinilla en este caso las cuentas están fechadas en la primera mitad del siglo II a.C. (VAQUERIZO, 1990)

BADAJOZ: Cancho Roano (Zalamea la Serena) (MALUQUeR y AubET, 1981) y Castrejón de Capote (Higuera la Real) (BERROCAL, 1988).

ÁVILA: La Osera (Chamartín de la Sierra). Los adornos de vidrio se encuentran hasta el momento inéditos ${ }^{4}$.

MALLORCA: Se encontraron en la necrópolis de Son Real y en la isla de los Porros (TARRADELL, 1964). Las cuentas polícromas se encuentran en Cales Coves.

\section{LAS CUENTAS DE «OJOS»DE EL CIGARRALEJO}

Hemos de recordar que el total de tumbas excavadas en El Cigarralejo es de 500 , solo tenían objetos de vidrio 87 . Las tumbas con cuentas de vidrio son 59. La totalidad de cuentas halladas es de 1018, de estas 79 están decoradas con “ojos» ${ }^{5}$ (gráf. 1) (cuadro 1).

Todas las cuentas oculadas pertenecen al grupo de cuentas estratificadas, concretamente a los tipos A y B de Eisen (Fig. 2-1 y 2-2), excepto un fragmento de cuenta procedente de la tumba 213 que por sus características formales estaría dentro del grupo C (Fig. 2-3).

La mayoría de las piezas son esféricas solo hay dos anulares. Existe una gran variedad cromática de las piezas, tanto del fondo como de la decoración.

El estudio morfológico de las perlas multicolores en relación a los datos cronológicos y antropológicos que proporcionan las tumbas del cementerio murciano permite establecer: a) El posible origen de las piezas oculadas; b) El uso de los adornos en función del sexo y c) El probable carácter mágico de las cuentas.

a) El tamaño de las piezas, los colores del fondo y la decoración con sus distintas variantes no difieren de los cientos de cuentas halladas en los

4 Los datos sobre las tumbas localizadas en las distintas zonas del cementerio y de los enterramientos que tenian cuentas nos han sido proporcionados por Isabel Baquedano quien actualmente realiza su Tesis Doctoral sobre la necrópolis situada en Chamartín de la Sierra. Los materiales se encuentran depositados en el Museo Arqueológico Nacional, y han sido consultados gracias a las facilidades dispensadas por la conservadora Dra. Alicia Rodero.

5 Se realizó una brevisima descripción de estas piezas en el estudio publicado en colaboración con los doctores Rincón y HoffMANN (V. Bibliografia). 
enterramientos ibicencos excavados por Román en Puig des Molins (19211929). Los ejemplares hallados en El Cigarralejo son sin lugar a duda importaciones de la isla ${ }^{6}$.

\section{CUADRO 1}

CUENTAS DE VIDRIO POLÍCROMAS DECORADAS CON «OJOS» PROCEDENTES DE EL CIGARRALEJO, MULA MURCIA

\begin{tabular}{|c|c|c|c|c|c|}
\hline Forma & Contexto & Diámetro & Altura & Cronologia & Frecuencia \\
\hline Esférica & $T-45$ & 0.00 & 0.00 & $350-325$ & 1 \\
\hline Estérica & T-4B & 0.00 & 0.00 & - & 4 \\
\hline Esférica & $T-75$ & 2.00 & 0.00 & $375-300$ & 1 \\
\hline Estérica & $T .75$ & 2.00 & 0.00 & $375-300$ & 1 \\
\hline Esférica & $\mathrm{T}-75$ & 2.00 & 0.00 & $375-300$ & 1 \\
\hline Estérica & T.75 & 0.80 & 0.00 & $375-300$ & 1 \\
\hline Esférica & $T .83$ & 1.10 & 0.50 & $425-375$ & 1 \\
\hline Estérica & $T-83$ & 0.70 & 0.50 & $425-375$ & 1 \\
\hline Estérica & $T-83$ & 0.10 & 0.50 & $425-375$ & 1 \\
\hline Esférica & T-99 & 0.00 & 0.00 & $375-300$ & 1 \\
\hline Estérica & $T-104$ & 1.30 & 0.00 & $400-350$ & 1 \\
\hline Estérica & $T-109$ & 1.30 & 0.00 & $375-300$ & 1 \\
\hline Esférica & T-152 & 0.00 & 0.50 & $375-350$ & 1 \\
\hline Estérica & $T-211$ & 0.00 & 0.00 & $400-375$ & 8 \\
\hline Estérica & T-213 & 0.00 & 0.00 & $425-375$ & 8 \\
\hline Estérica & $T-239$ & 2.50 & 0.00 & $350-325$ & 1 \\
\hline Estérica & T-239 & 2.50 & 2.00 & $350-325$ & 1 \\
\hline Estérica & T-239 & 0.00 & 0.00 & $350-325$ & 1 \\
\hline Estérica & $T \cdot 244$ & 0.00 & 0.00 & $375-350$ & 1 \\
\hline Estérica & $T-427$ & 0.00 & 0.00 & $400-350$ & 1 \\
\hline Estérica & $T-247$ & 0.00 & 0.00 & $400-350$ & 5 \\
\hline
\end{tabular}

Agradecemos al Doctor Emeterio Cuadrado las facilidades que nos dió en todo momento para estudiar los materiales de vidrio inéditos de la necrópolis de El Cigarralejo.

6 Estamos realizando en la actualidad un estudio pormenorizado de las cuentas prerromanas encontradas en las necrópolis de lbiza, concretamente las halladas en las excavaciones realizadas por Román en los años 1921-1929. La abundancia de los materiales permite proponer una primera tipología. Hemos de advertir que aunque las cuentas se encuentran sacadas de su contexto, responden a las halladas por Román, como puede comprobarse por los collares enfilados y publicados en las correspondientes Memorias de Excavaciones. Las cuentas publicadas y las inéditas que proceden de contextos con cronologias mas precisas no difieren de las halladas por Román. 
CUADRO 1 (Continuación)

\begin{tabular}{|c|c|c|c|c|c|}
\hline Forma & Contexto & Diámetro & Altura & Cronología & Frecuencia \\
\hline Esférica & T-252 & 0.00 & 0.00 & $400-350$ & 1 \\
\hline Esférica & $T-266$ & 0.00 & 2.20 & $400-375$ & 1 \\
\hline Estérica & T-268 & 0.00 & 0.00 & $400-375$ & 1 \\
\hline Estérica & $T-268$ & 0.00 & 0.00 & $400-375$ & 1 \\
\hline Estérica & $T-277$ & 0.00 & 1.60 & $425-375$ & 1 \\
\hline Estérica & T-277 & 1.80 & 0.00 & $425-375$ & 1 \\
\hline Estérica & $T-281$ & 0.00 & 0.00 & $350-325$ & 1 \\
\hline Esférica & T.281 & 0.00 & 0.00 & $350-325$ & 1 \\
\hline Esférica & T.281 & 1.70 & 0.00 & $350-325$ & 1 \\
\hline Estérica & T-281 & 1.60 & 0.00 & $350-325$ & 1 \\
\hline Esférica & T-293 & 1.50 & 0.00 & $375-350$ & 1 \\
\hline Estérica & T-293 & 1.50 & 0.00 & $375-350$ & 1 \\
\hline Esférica & T-293 & 1.20 & 0.00 & $375-350$ & 1 \\
\hline Esférica & T-294 & 1.60 & 0.00 & $350-325$ & 1 \\
\hline Esférica & T-327 & 1.40 & 0.00 & $375-350$ & 1 \\
\hline Esférica & T-349 & 1.30 & 0.00 & $375-350$ & 1 \\
\hline Estérica & T-358 & 1.00 & 0.00 & $400-350$ & 1 \\
\hline Estérica & $T-398$ & 1.50 & 1.20 & V-II a.C. & 1 \\
\hline Esférica & T-406 & 0.95 & 0.55 & V.\|l a.C. & 1 \\
\hline Esférica & T-406 & 0.00 & 0.00 & V-\|l a.C. & 1 \\
\hline Esférica & T-439 & 1.40 & 1.20 & V. $\|$ a.C. & 1 \\
\hline Estérica & T-439 & 1.70 & 1.00 & V-ll a.C. & 1 \\
\hline Esférica & T-441 & 1.00 & 0.90 & V-\|l a.C. & 1 \\
\hline Esférica & $T-452 \mathrm{~B}$ & 0.00 & 0.00 & V-II a.C. & 1 \\
\hline Estérica & $T-475$ & 0.00 & 0.00 & V-\|ll a.C. & 1 \\
\hline Estérica & T-480 & 1.30 & 0.90 & V-II a.C. & 1 \\
\hline Esférica & T-480 & 0.00 & 0.00 & V-II a.C. & 1 \\
\hline Estérica & T-484 & 1.20 & 0.90 & V-\|l a.C. & 1 \\
\hline Estérica & $\mathrm{T}-484$ & 1.20 & 0.80 & V-\|ll a.C. & 1 \\
\hline Estérica & T.515 & 0.00 & 0.00 & V-II a.C. & 2 \\
\hline Estérica & T-515 & 0.00 & 0.50 & V-II a.C. & 1 \\
\hline Cilíndrica & $T-213$ & 0.00 & 0.00 & 425-375 a.C. & 1 \\
\hline Anular & T.407 & 0.00 & 0.00 & V.II a.C. & 1 \\
\hline Anular & T-524 & 0.00 & 0.00 & V.\|l a.C. & 1 \\
\hline \multicolumn{6}{|c|}{ TOTAL } \\
\hline
\end{tabular}


La existencia en la tumba 213 de una cuenta oculada adornada con protuberancias al borde difiere notablemente de los tipos mas abundantes A y $B$ de Eisen y seguramente se realizó en un taller distinto probablemente de Cartago, como una de las cuentas halladas en la tumba $n^{\circ} 33$ de La Albufereta (Alicante) (RUANo, 1995,194).

b) Las cuentas se encontraron en tumbas con cronologías del siglo $\mathrm{V}$ II a.C. Los estudios osteológicos permiten conocer el sexo de los individuos enterrados, aunque a veces es difícil precisar este dato, debido a la ausencia de restos (SANTONJA, 1995). Las cuentas oculadas formaron parte de 35 tumbas: 16 femeninas; 2 masculinas y 6 de niños. Existen once cremaciones en las que no se ha podido determinar el sexo. Estos datos permiten afirmar que las cuentas de "ojos" fueron usadas sin diferencias netas en cuanto a la edad y sexo aunque es obvia su mayor presencia en tumbas femeninas (Cuadros 2 al 9).

La inclusión de elementos de adorno en la tumba 404 perteneciente a un niño nos informa de la existencia de prestigio por vínculos de sangre en el mundo ibérico, como sugiere Lull para la Cultura del Argar $(1983,445)^{7}$.

c) Como ya expusimos en un trabajo anterior (Ruano, 1995,198) podemos formular la siguiente pregunta: ¿Cumplieron las cuentas vítreas de "ojos", otra función añadida o complementaria de la meramente ornamental ? La respuesta no es contundente, pero no podemos descartar, aunque sea como conjetura, que tuvieran un posible valor apotropaico. Según Dubin la ideología del mal de ojo es compleja. Diferentes culturas interpretan sus efectos de diferentes formas y los remedios y las medidas preventivas varían de unas culturas a otras. El poder de la mirada es considerado generalmente como dañino, sin embargo la mirada fija de algunos dioses (por ejemplo Horus, en Egipto) es considerada beneficiosa. Los «ojos» están frecuentemente representados en amuletos o pintados en el interior de los edificios o tumbas para contrarrestar el mal de ojo. El autor afirma: "Los collares de cuentas oculadas simbolizan la fuerza protectora que mantienen al niño a salvo en los momentos que los ojos de la madre se desvian temporalmente».

\footnotetext{
7 "Los cálculos estimativos de la diferente estratificación social de cada una de las comunidades donde fue posible el análisis, nos permitió demostrar que en algunas ocasiones se enterraba ya al niño con un rico ajuar, lo que implica a todas luces el paso de una sociedad cuyo sistema de funciones individuales se deben a la actividad, edad y representación de cada uno de sus miembros, a otra donde esos derechos se obtienen" (LULL, 1983, 445).
} 
Cuentas policromas decoradas con "ojos"

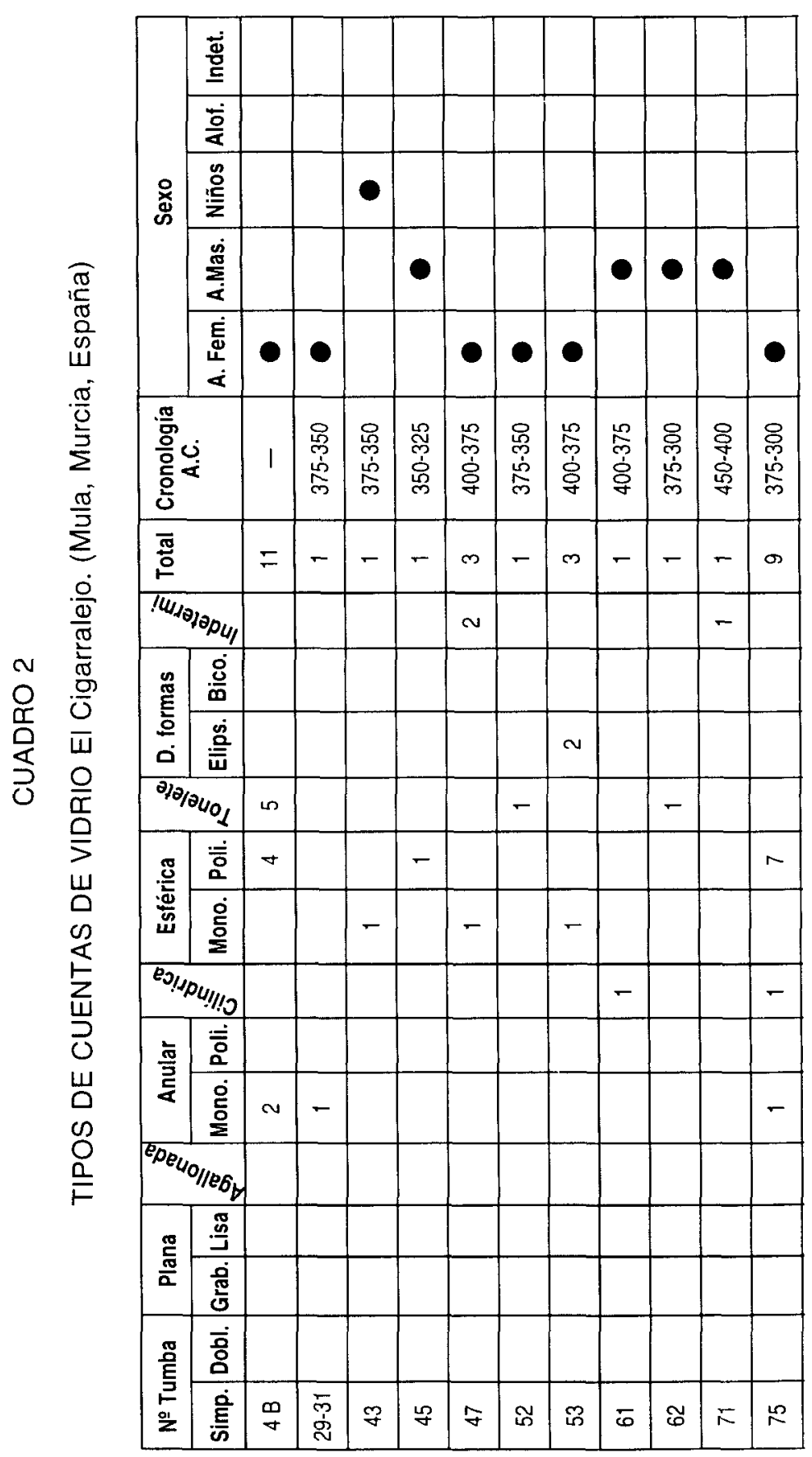




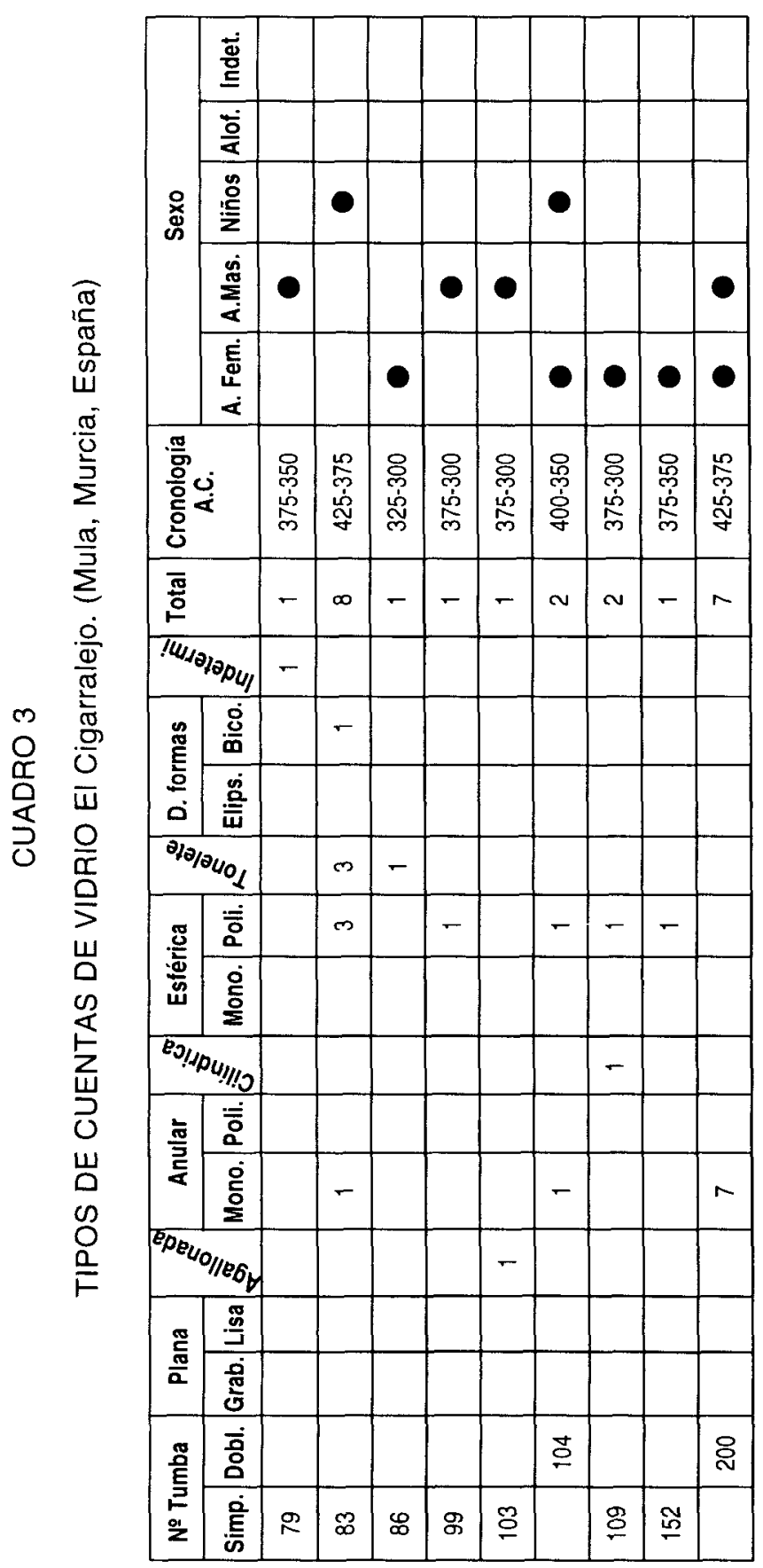




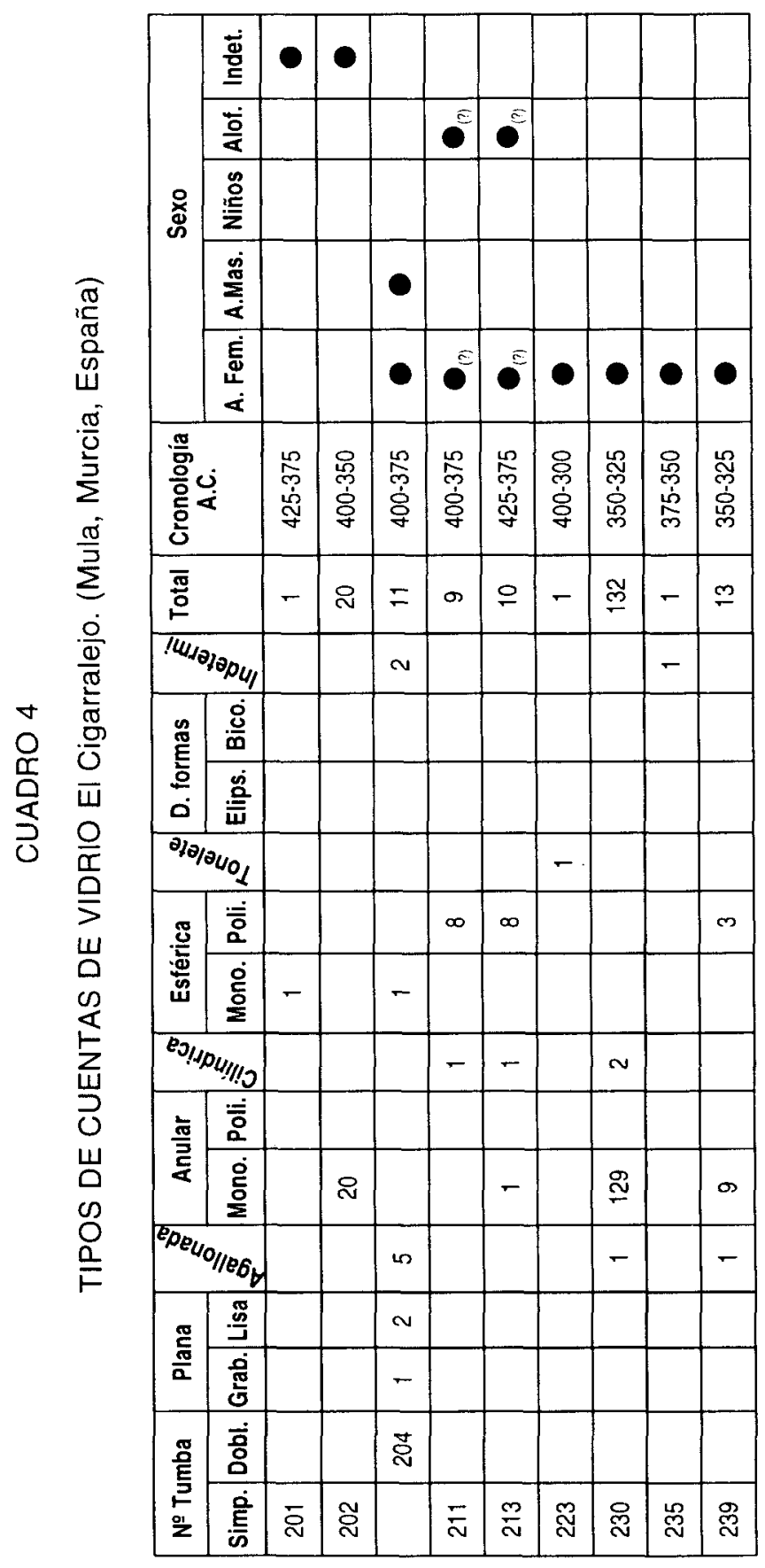




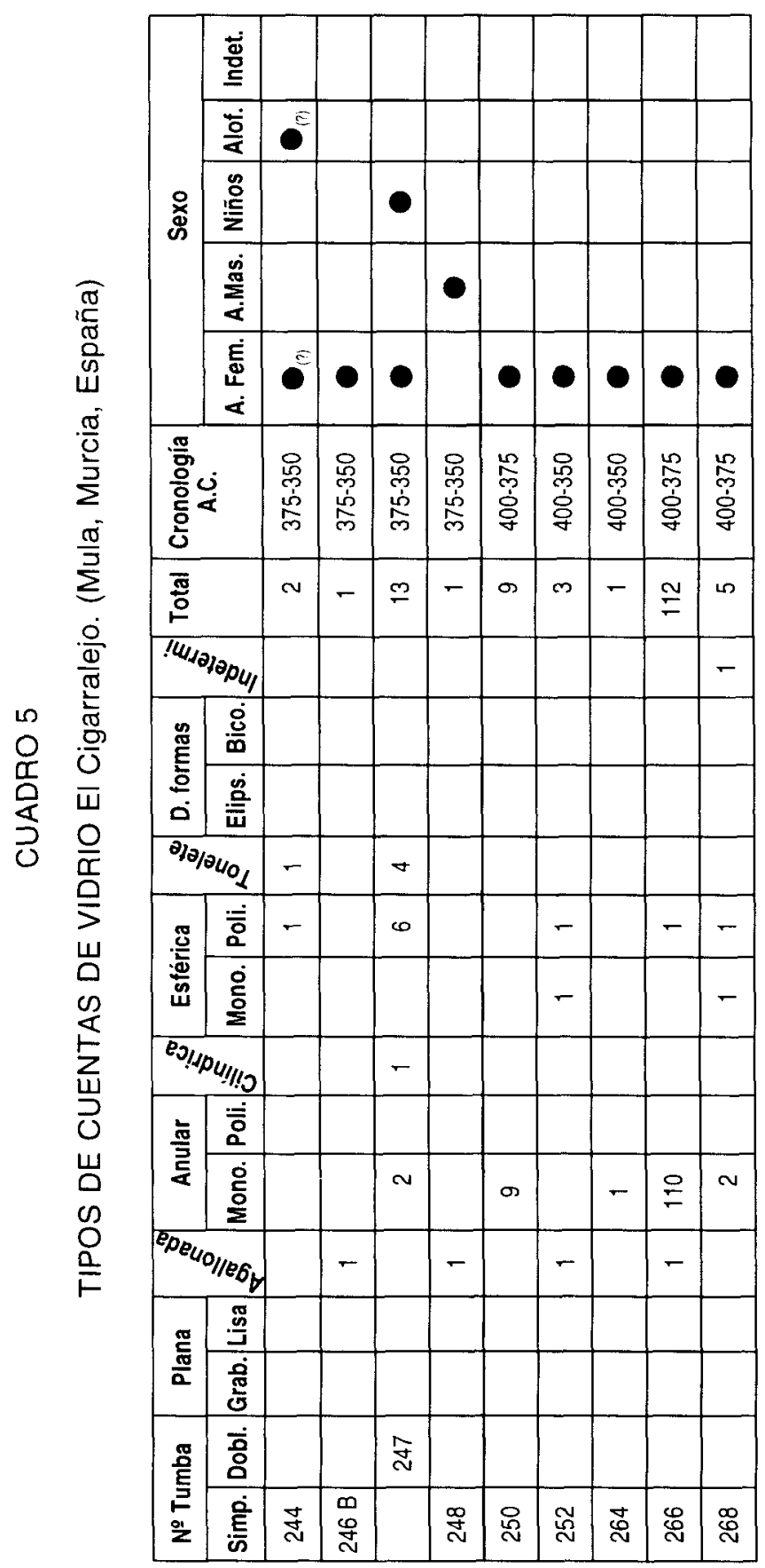




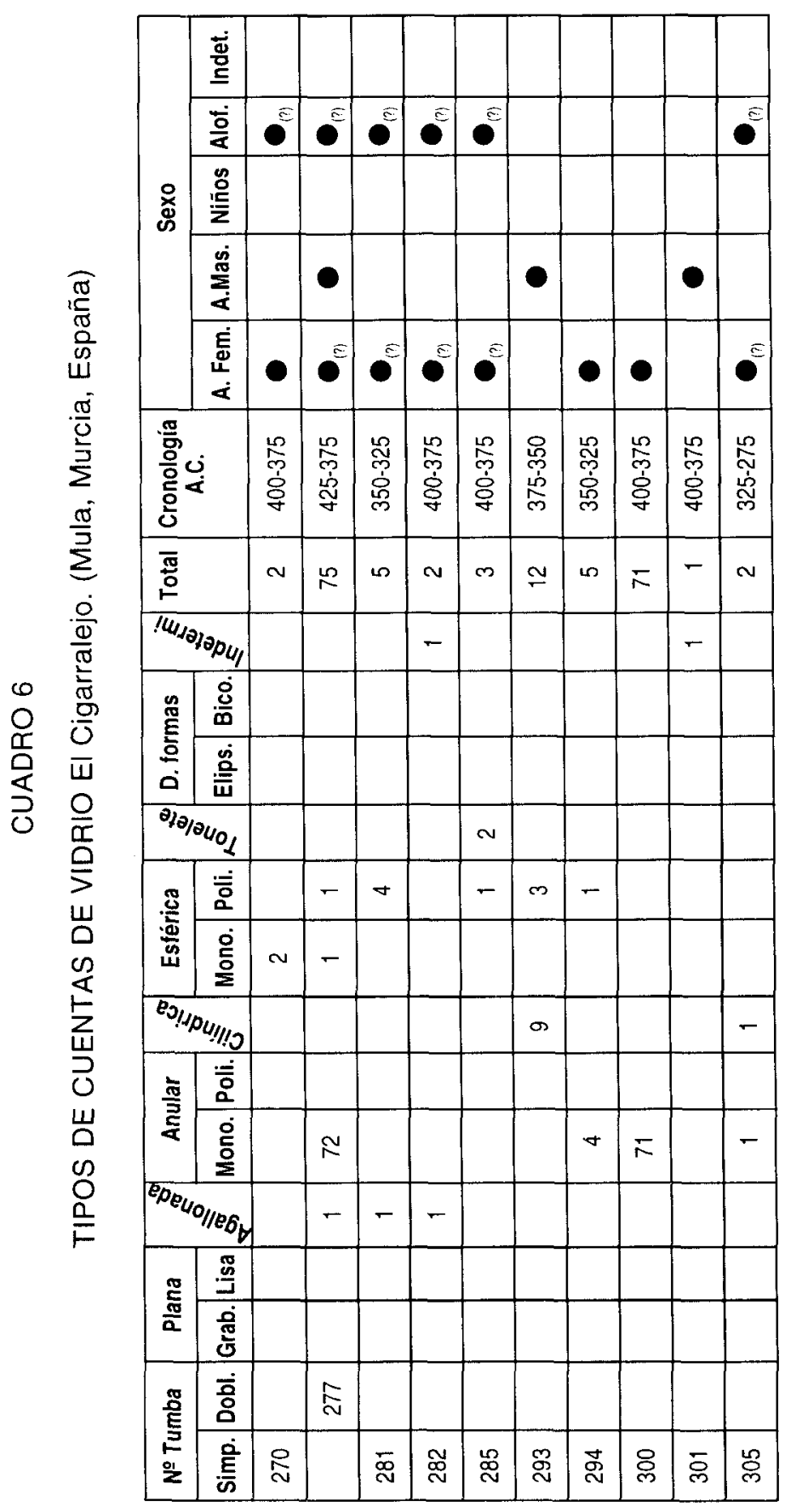




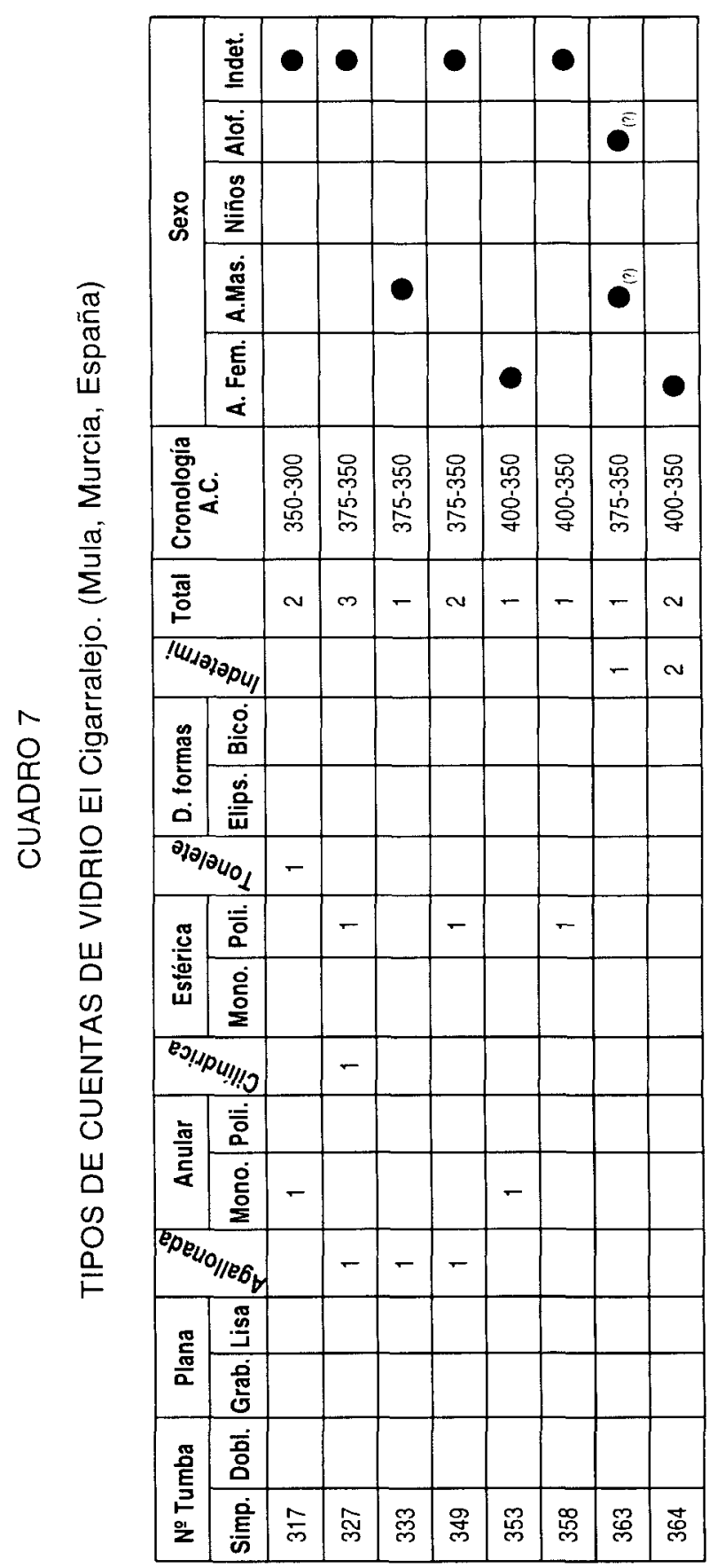




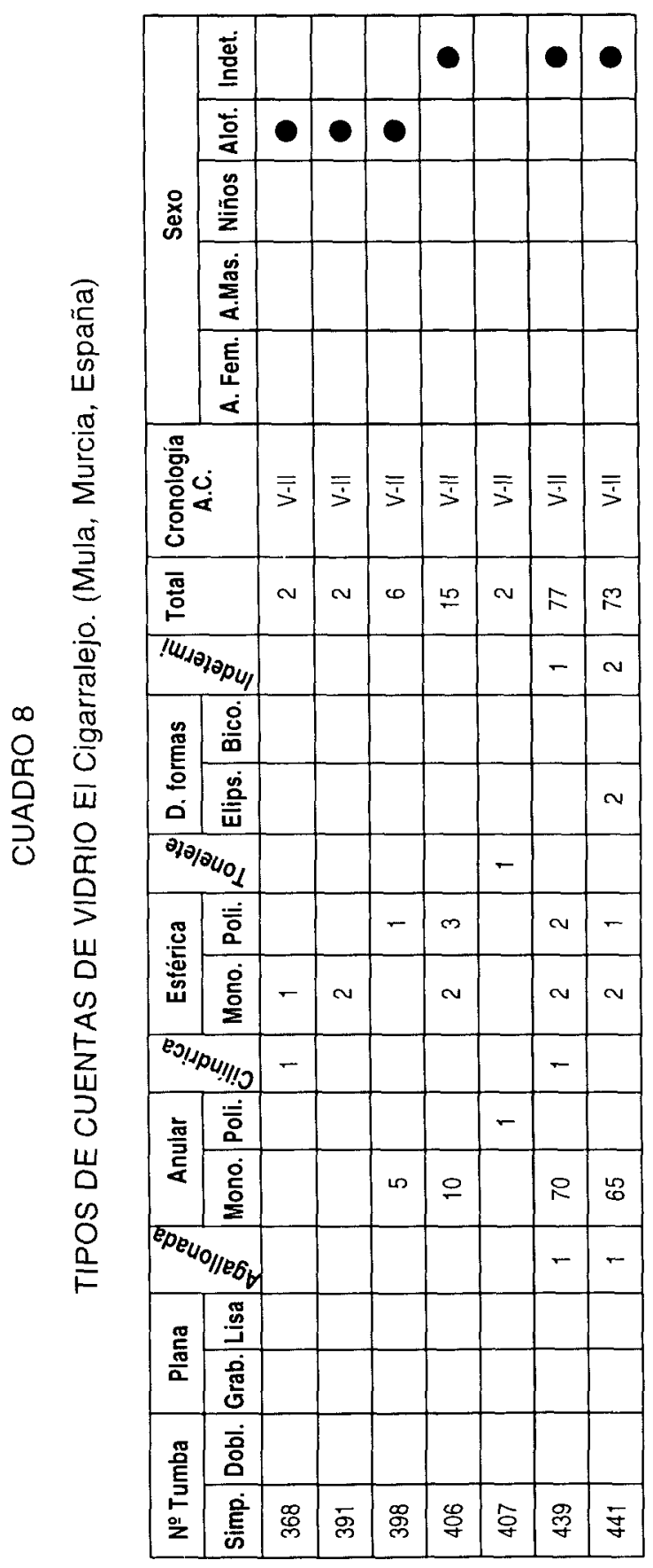




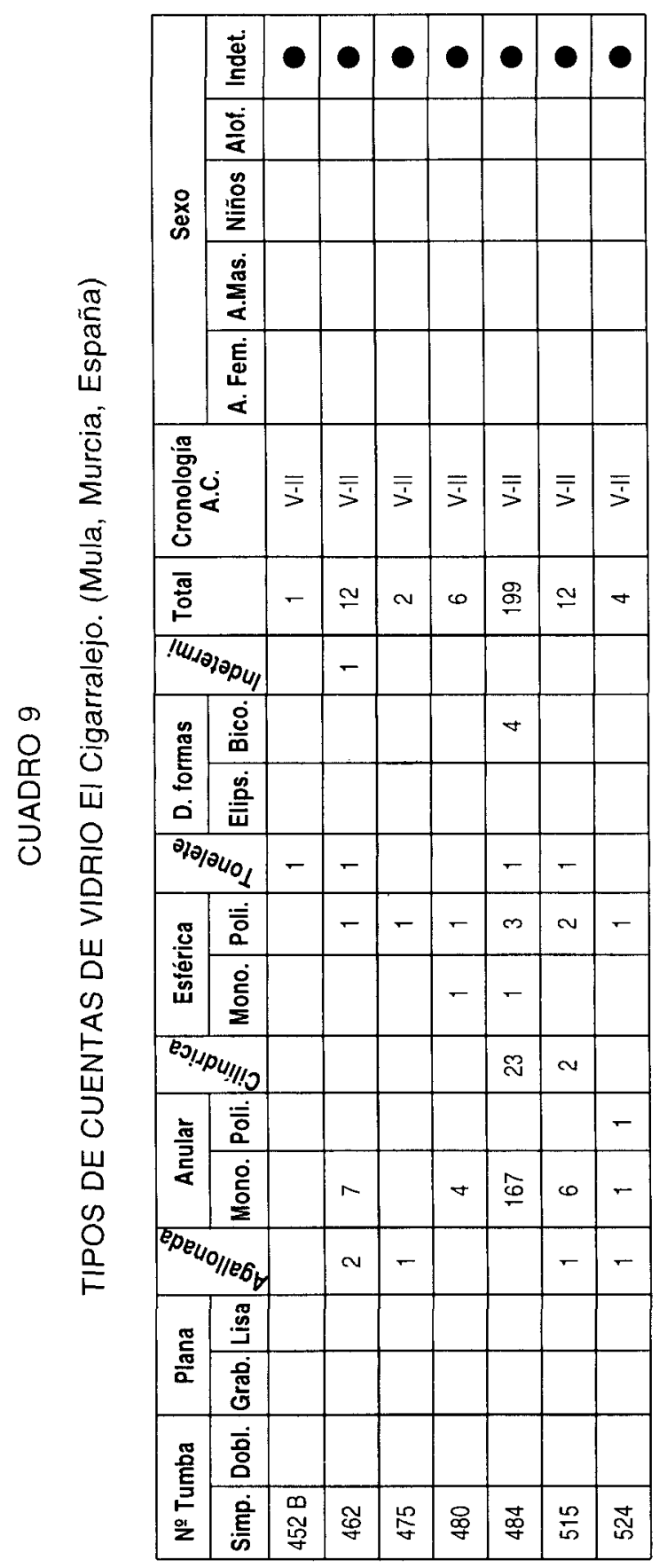



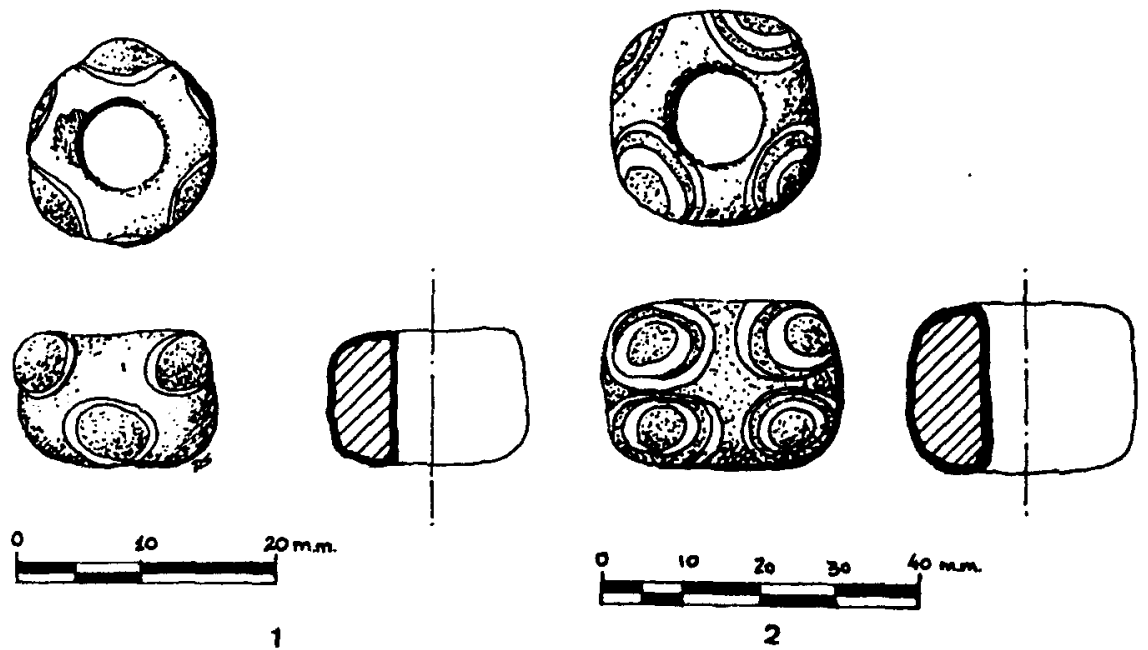

1
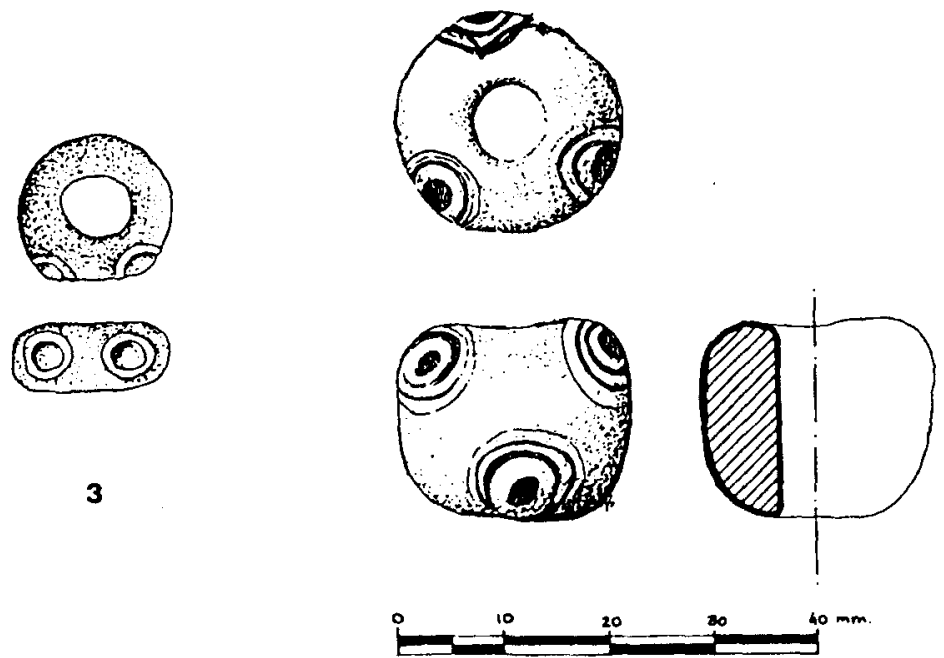

4

Figura 8. Diferentes cuentas halladas en la necrópolis de El Cigarralejo (Mula, Murcia): 1: Tumba no 368; 2: Tumba no 484; 4: Tumba $n^{\circ}$ 391. 3: Cuenta de "ojos" procedente del Alto Urgel (Cura Morera, 1973). 
En tal sentido se pronuncia Labatut al observar un collar procedente de Crimea publicado por Dechelette en el que junto con amuletos se entremezclan cuentas oculadas (Fig. 9).

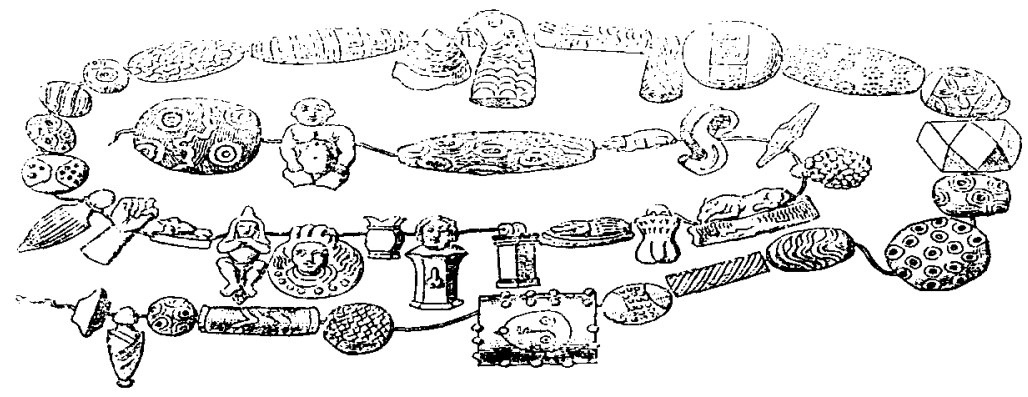

Figura 9. Collar con amuletos y cuentas procedente de Kerch, Crimea (Dechelette, 1927).

Éste pudiera ser el caso que observamos en seis tumbas infantiles de El Cigarralejo y más concretamente en la tumba 406, donde precisamente la cuenta de «ojos", se encuentra incluida en un collar con un amuleto de hueso que representa un brazo con la mano cerrada y el pulgar entre los dedos índice y corazón (Fig. 10)

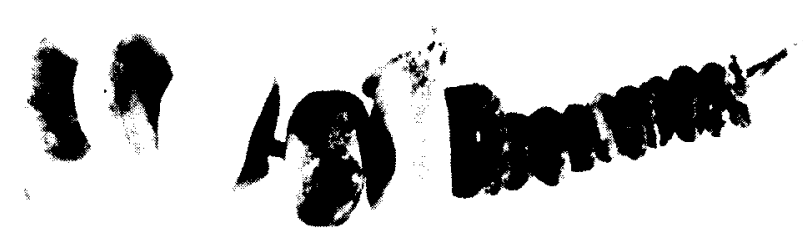

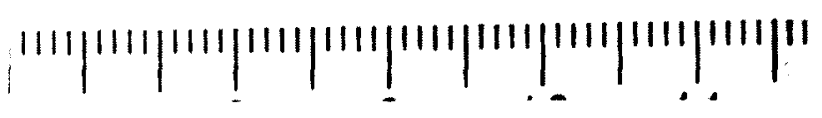

Figura 10. Collar con amuleto de hueso y cuentas de vidrio donde se incluye una cuenta oculada procedente de la tumba 406 de El Cigarralejo (Mula,

Murcia). 
SINTTESIS FINAL

Las cuentas de vidrio polícromas oculadas se encuentran en mayor o en menor número en contextos arqueológicos prerromanos. Hasta el momento la cuenta con cronología más antigua, data del año 1400 al 1100 a.C. y la más moderna se situaría en el siglo II a.C.

El proceso de fabricación de las cuentas decoradas con "ojos" requiere técnicas muy precisas conocidas a través de los trabajos de Eisen, basándonos en este autor hemos realizado un cuadro donde se contemplan los tipos principales.

El estudio pormenorizado de la necrópolis de El Cigarralejo permite afirmar que de las 500 tumbas excavadas sólo 87 tenian objetos de vidrio, 59 tumbas tenian un total de 1.018 cuentas de collar y de éstas 79 eran oculadas.

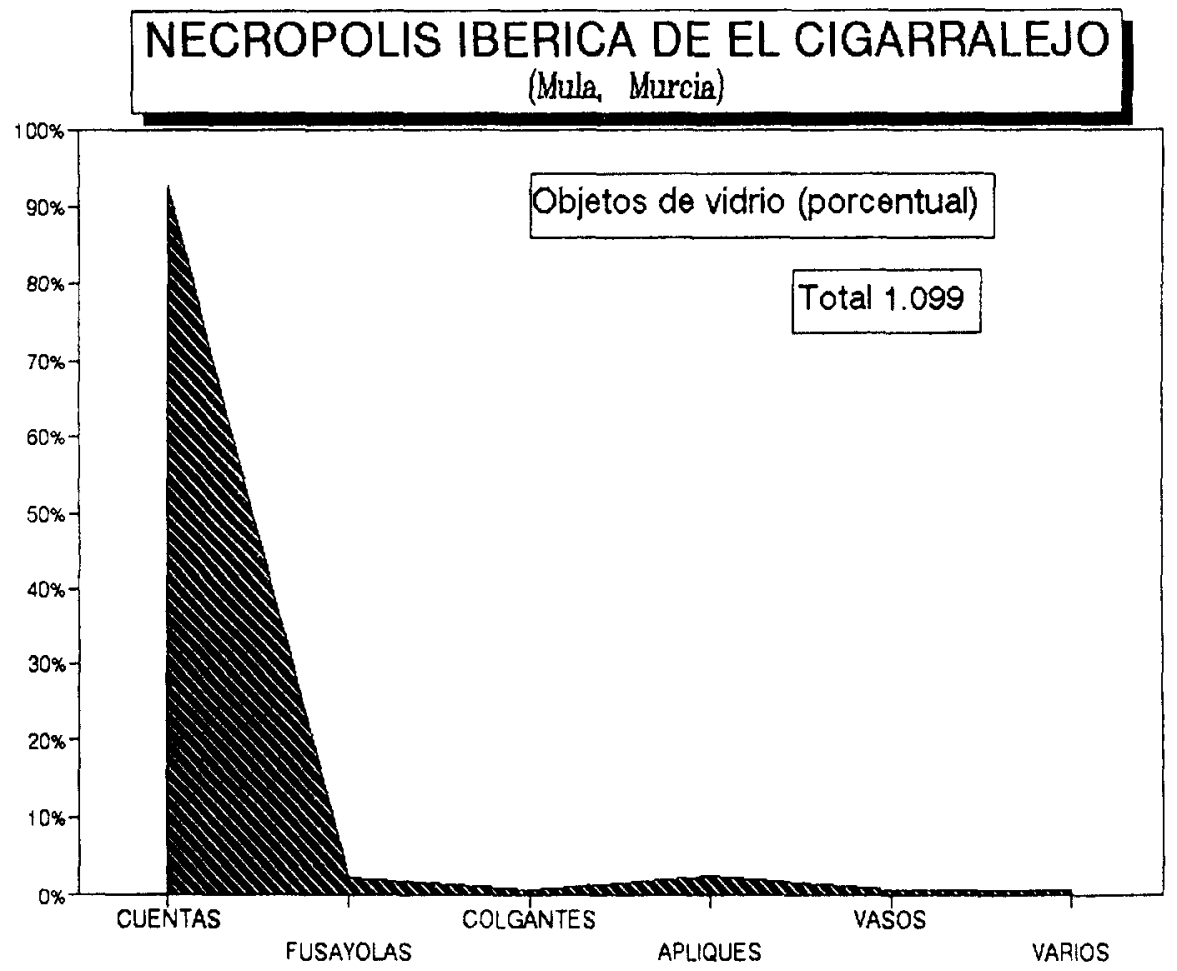

Gráfico 1. Objetos de vidrio procedentes de la necrópolis ibérica de El Cigarralejo (Ruano et alii, 1995). 
Las cuentas multicolores de la necrópolis murciana parecen realizadas en un taller ibicenco, excepto la hallada en la tumba 213 que pudiera proceder de Cartago.

Las cuentas de «ojos» se usaron sin discriminación de sexo ni edad.

No se puede descartar, a manera de conjetura y siguiendo la teoría de Dubin el carácter apotropaico de esta clase de ornato, sobre todo si tenemos en cuenta la perla con "ojo" protector usada en vida y depositada en la tumba 406 de El Cigarralejo.

El collar con cuentas y amuletos de la mencionada tumba 406 donde se enterró un niño, sugiere la existencia de prestigio en los niños por vínculos de sangre.

\section{BIBLIOGRAFIA}

Almagro BASCH, M. (1953-1955): Las necrópolis de Ampurias, vol. I. Introducción y necrópolis griegas, vol. II. Necrópolis romanas y necrópolis indígenas. Barcelona.

Almagro GoRBeA, M. (1965): "La necrópolis celtibérica de Las Madrigueras, Carrascosa del Campo (Cuenca)". Excavaciones arqueológicas en España, 41. Madrid.

Almagro Gorbea, M. (1973): "Los campos de túmulos de Pajaroncillo (Cuenca)". Excavaciones arqueológicas en España, 83. Madrid.

Almagro Gorbea, M.(1977): El Bronce Final y el periodo orientalizante Extremadura. Bibliotheca Praehistorica Hispana, XIV. Madrid.

Almagro Gorbea, M. (1989): La necrópolis de Medellin. Influencia fenicia en los rituales finerarios tartésicos. Madrid.

ALEKSEJEVA, J.M. (1975): “Antienyje busy Severnogo Priernomor'ja".Archeologija SSSR. Svod archeologiecskich istocnikov, vypusk G 1-12, Moscow.

ALEKSEJEVA, J.M. (1978): "Antienyje busi Severnogo Oriernomor'ja". Archeologija SSSR. Svod archeologiecskich istocnikow, vypusk $\mathrm{G}$ 1-12. Moscow.

AstRUC, M. (1951): “La necr6polis de Villaricos". Informes y Memorias, 25. Madrid.

BARTHELEMY, M.(1992): "Producciones artesanales fenicio-púnicas." Primeras Jornadas de Arqueologia Fenicio-Púnica. Ibiza.

Berrocal, L. (1988): “Excavaciones en Capote. Beturia céltica".Serie Nertobrigense, I. Fregenal de la Sierra, Higuera la Real (Badajoz).

Blázouez, J.M. a ; García Gelabert, M.P. (1988): Castulo, Jaén, España. Excavaciones Arqueológicas en la necr6polis ibérica del Estacal de Robarinas. Siglo IV a.C.

Broncano, S.; Martin, A.; Negrete, M. y PuCH, E. (1985): “La necrópolis ibérica de El Tesorico (Agramont, Hellfn, Albacete)". Noticiario Arqueológico Hispánico, 20, 45-121. Madrid.

Cuadrado, E (1987): Las necrópolis ibérica de El Cigarralejo, Mula, Murcia. Bibioteca Praehistorica Hispana. Madrid.

Cruz Pérez, M.L. (1990): "La necrópolis ibérica de Los Nietos (Cartagena, Murcia)". Excavaciones arqueológicas en España, 158. Madrid.

CuRA Morera, M. (1973): "Una cuenta de pasta vitrea procedente de un sepulcro megalítico de l'Alt Urgel", Ampurias, XXXV, 213-215, Barcelona.

DECHELETTE, J. (1908): Manuel:d'archeólogie préhistorique, celtique et gallo-romaine, vol. 1-8. París.

DuBín, L.S. (1987): The History of Beads, Thames and Huston. London.

EISEN, G. (1916) a: "Button Bead. With special reference to those of the Etruscan an Roman periods". American Journal Archeology, XX, London, 299-302, New York.

EISEN, G. (1916) b: "The Caracteristic of Eye-Beads from Earliest Times to the present". American Journal of Arqueology, XXX, London, New-York. 
Figueras Pacheco, F. (1952): "Esquema de la necrópolis cartaginesa de Alicante". Archivo de Prehistoria Levantina, 111: 179-194, Valencia.

Figueras PACHECO, F. (1957): "Los vidrios fundidos del Alto Sureste Español». V Congreso Nacional de Arqueología, Zaragoza.

Gómez Bellard, C. (1984): "La necrópolis del Puigs de Molins (Ibiza). Campaña de 1946". Excavaciones arqueológicas en España, 157. Madrid.

González Pena, Ma.L. (1984): Vidrios españoles. Madrid.

González Prat, A (1983): "Estudio arqueológico del poblamiento en la Peña Negra de Crevillente." Lucentum, Anejo I, Alicante.

HAEVERNICK, T.E. (1961): "Cuentas de vidrio de el Museo Arqueológico Nacional de Madrid". Archivo Español de Arqueología XXXIV, 103-104, 209-210, Madrid.

HAEVERNICK, T.E. (1972): "Perlen mit zusammengesetzten Augen (compound)-eye beads". Prähistorische Zeitschtif, 47:151-156.

HAEVERNICK, T.E. (1974): "Zu den Glasperlen in Slowenien». Opuscula Castelic, Ljubljana, 6165.

KISA, A. (1908): Das glas in Altertume. Leipzig.

LAFUENTE, J. (1934): “Excavaciones en La Albufereta de Alicante (antigua Lucentum)". Junta Superior de Excavaciones y Antigüedades, 126, Madrid.

LULL, V. (1983): La cultura del Argar. Un modelo para el estudio de las formaciones económico sociales prehistóricas, Akal. Madrid.

Maluquer, J. (1974): "La necropolis de la Loma del Peinado, Casillas de Martos (Jaén)" Programa de Investigaciones Protohistóricas, 6. Barcelona.

Maluquer, J. y Aubet, M.E. (1981): El Santuario Protohistórico de Zalamea la Serena, Badajoz, Badajoz.

mata Porreño, C. (1991): Los Villares, Caudete de las Fuentes. Origen y evolución de la Cultura lbérica, Valencia.

Molina FAJARDO, F. y HuerTAS Jiménez, C. (1985): Almuñecar en la antigüedad. La necrópolis fenicio -punica de Puente Noy Maracena (Granada), Granada.

Perdigones, L; Muñoz Vicente, A., y Pisano, G. (1990): "La necrópolis fenicio púnica de Cádiz", siglos VI-IV a.C. Studia Punica, 7. Roma.

Pujol, A. (1989): La población prerromana del extremo nordeste Peninsular. Génesis y desarrollo de la cultura ibérica en las comarcas gerundenses, vol. 1-2, Barcelona.

Quintero Atauri, P. (1932): "Excavaciones de Cádiz, Memoria de las Excavaciones practicadas en 1921-1931\%. Memorias de la Junta Superior de Excavaciones Arqueológicas.

RomÁn FERrER, C. (1913): Antigüedades Ebusitanas. Tipografía La Academia. Barcelona.

Román Ferrer, C. (1918): "Excavaciones en Cala d'Hort Ibiza (Baleares). Memoria de los resultados obtenidos en las excavaciones y exploraciones practicadas en el año 1917". Memoria de la Junta Superior de Excavaciones Arqueológicas, 20. Madrid.

Román FerRer, C. (1921): “Excavaciones en los diversos lugares de la isla de lbiza. Memoria de los resultados obtenidos en las excavaciones practicadas en 1919 y 1920 ". Memoria de Junta Superior de excavaciones Arqueológicas, 43. Madrid.

RomÁn FERRER, C. (1922): "Excavaciones en los diversos lugares de la isla de Ibiza". Memorias de los resultados obtenidos en la excavaciones practicadas en 1921, Memoria de la Junta superior de Excavaciones Arqueológicas, 46. Madrid.

RomÁn FERRER, C. (1923): “Excavaciones en Ibiza. Memoria de los resultados obtenidos en las. excavaciones practicadas en 1922". Memoria de la Junta Superior de Excavaciones Arqueológicas, 58. Madrid.

RomÁn FerRer, C. (1924): “Excavaciones en lbiza. Memoria de los resultados obtenidos en las excavaciones practicadas en 1924". Memoria de la Junta Superior de Excavaciones Arqueológicas, 68 . Madrid.

RuAno Ruiz, E. (1995): "El collar con cuentas y colgantes de vidrio procedente de La Albufereta (Alicante)». Boletín de la Asociación de Amigos de la Arqueologia, 36, 193-203. Madrid.

Ruano Ruiz, E.; HOFFMAN, P. y Rincón, J.Ma (1995): “Aproximación al vidrio prerromano: Los materiales procedentes de la necrópolis ibérica de El Cigarralejo (Mula, Murcia). Composición quimica de varias cuentas de collar". Trabajos de Prehistoria, 52-1, 189-206. Madrid.

Ruano Ruiz, E. (En prensa) a: “Perles en verre preromaines provenant de La nécropole iberique de El Cigarralejo, Mula, Murcia, España. Siecles V-II a.C. Internationales Perlencolloquium im Reiss Museum, Mannhein (Alemania). 
Ruano Ruiz, E. (En prensa) b: La colección Costa Picarol en el Museo de lbiza "Las cuentas de collarm.

Ruano Ruiz, E. et alii (En prensa) c: Cuentas de vidrio halladas en las necrópolis púnicas de Ibiza depositadas en el Museo Monográfico de Puig des Molins (España): Ensayo tipológico $y$ análisis químico de algunos materiales.

SANTONJA, M. (1993): "Estudio osteológico. Necrópolis ibérica de El Cigarralejo, comparada con los ajuares". Espacio Tiempo y Forma. Serie 1I. 6, 297-347. Madrid.

SLEEN, W.G. (1973): A Hand books on beads, Lieja.

SPAER, N. (1985): "Some observations on the stratified Mediterranean eye-beads of the first miIlennium BC “. Annales du 10 Congrés de L'association Internationale pour l'Histoire du verre", Madrid-Segovie 23-28 Septembre. Segovia.

TARRADELL, M. (1964): "La necrópolis de Son Real y la lila dels Porros". Excavaciones Arqueológicas en España, 24, Madrid.

Vaquerizo, N. (1990): El yacimiento ibérico del Cerro de la Cruz (Almedinilla, Córdoba). Córdoba.

VENCLOVA, N. (1983): "Prehistoric eye beads in central Europe», Journal of glass Studies, vol. 25. 